\title{
Deposição da calda pulverizada por três pontas de pulverização sob diferentes condições meteorológicas
}

\section{Deposition of the spraying suspension for three spray nozzles under different meteorological conditions}

\author{
Marcelo Gonçalves Balan ${ }^{1 *}$; Otavio Jorge Grigoli Abi-Saab²; \\ Cristhiane Gonzaga da Silva ${ }^{3}$; Alexandre do Rio ${ }^{3}$
}

\begin{abstract}
Resumo
Nas pulverizações agrícolas geralmente é dada muita importância aos produtos fitossanitários e pouca à técnica de aplicação, sendo que as perdas podem ultrapassar $70 \%$ do total aplicado. A alta temperatura e a baixa umidade relativa do ar têm importante efeito sobre a pulverização de produtos fitossanitários, causando evaporação mais rápida das gotas. O objetivo deste trabalho foi avaliar a variação da deposição da calda de pulverização com três tipos de pontas (jato cônico vazio, jato plano e antideriva) nas diferentes horas do dia. Uma solução salina foi aplicada em copos de PVC, aos quais, foram adicionados água destilada e deionizada, para leitura da condutividade elétrica. De maneira geral as pontas de pulverização de jato plano e antideriva não tiveram a deposição afetada pela variação da temperatura e umidade relativa do ar e não diferiram entre si, mas o mesmo não ocorreu com a ponta de jato cônico vazio onde a variação foi de mais de $100 \%$. Os resultados mostraram que a deposição das gotas produzidas pela ponta de jato cônico vazio foi significativamente afetada pela variação das condições meteorológicas. Palavras-chave: Produto fitossanitário, temperatura, umidade relativa, tecnologia de aplicação
\end{abstract}

\begin{abstract}
In the agricultural sprays more importance is generally given to the pesticide and less to the application technique, though the losses can overpass $70 \%$. The high temperature and the low relative humidity of the air have important effects on the spraying of pesticides, causing faster evaporation of the drops. The objective of this research was to evaluate the variation of the deposition spray with three types of nozzles in different hours of the day (hollow cone, reduced drift and air inclusion). A saline solution was applied in PVC glasses to which distilled water was added for electric conductivity reading. In a general way the deposition of the flat fan nozzles and the anti-drift ones had no difference and was not affected by the variation of the temperature and relative humidity, but the hollow cone nozzle presented variations of more than $100 \%$. The results showed that the hollow cone deposition was significantly affected by meteorological conditions variations.
\end{abstract}

Key words: Pesticide, temperature, relative humidity, spray technology

1 Eng ${ }^{\circ}$ Agrônomo, MSc., doutorando no Programa de Pós-graduação em Agronomia, Bolsista CNPq, Universidade Estadual de Londrina, E-mail: balan@uel.br

2 Eng ${ }^{\circ}$ Agrônomo, Prof. Doutor, Departamento de Agronomia, UEL, Londrina, PR

3 Discente de Agronomia, UEL, Londrina, PR

* Autor para correspondência 


\section{Introdução}

Predomina o consenso de que os produtos fitossanitários são prejudiciais ao homem (CUNHA et al., 2003). No entanto, o seu uso tem contribuído para a agricultura garantindo a expressão de seu potencial produtivo, baixando os custos e melhorando a qualidade dos alimentos. Sua utilização deve ser feita de maneira racional, dentro do contexto mais amplo da proteção integrada de plantas. Minimizase assim a contaminação do ambiente, os danos à saúde do homem e o aparecimento de pragas, doenças e plantas daninhas resistentes. Christofoletti (1997) descreve a aplicação como o processo de depositar o produto químico no alvo, sendo maior a sua ação quanto maior for a quantidade sobre a superfície deste. Entretanto, é dada muita importância ao produto fitossanitário e pouca à técnica de aplicação. As perdas nas aplicações em pulverização podem ultrapassar $70 \%$, conforme Chaim, Valarini e Pio (2000). Outros autores verificaram perdas entre 30\% e 50\% (BUISMAN et al., 1989; PERGHER; GUBIANI; TONETTO, 1997). No passado dispensava-se pouca atenção à uniformidade e tamanho de gotas produzidas em aplicações de produtos fitossanitários uma vez que se buscava era o bom molhamento da cultura mediante ao emprego de altos volumes de calda, de acordo com CARRERO (1996). Hoje há tendência de diminuição de volume de calda com a intenção de redução de custos e aumento da eficiência das pulverizações (SOARES; LEÃO, 2008). Portanto, o conhecimento da forma de aplicação torna-se de fundamental importância para garantir que o produto alcance $o$ alvo de forma eficiente, minimizando-se as perdas. Para isso, é necessário uniformidade de aplicação e espectro de gotas adequado.

Teixeira (1997) afirma existirem diferentes técnicas de aplicação de produtos fitossanitários sendo mais usuais aquelas baseadas na pulverização hidráulica devido ao seu amplo espectro de possibilidades de trabalho. Os pulverizadores hidráulicos vão desde simples pulverizadores costais até os modernos pulverizadores de barra (autopropelidos). Independente de sua complexidade, esses equipamentos têm nas pontas de pulverização, um de seus principais componentes que garantem a qualidade e a segurança da aplicação (TEWARI; MURALIKRISHNA; PANDYA, 1998). Christofoletti (1999) define o bico de pulverização como o conjunto de peças colocado no final do circuito hidráulico, através do qual a calda é emitida para fora da máquina. Esse conjunto é composto de várias partes, das quais a ponta de pulverização é a mais importante, regulando a vazão, o tamanho das gotas e a forma do jato emitido.

O conhecimento das condições de trabalho e o desempenho das pontas de pulverização, para Christofoletti (1999), são fundamentais quando se busca uma aplicação adequada, eficiente e econômica. Womac, Goodwin e Hart (1997) afirmam que a escolha e o uso adequado de bicos de pulverização constituem passos importantes para a melhoria das condições de precisão e segurança na aplicação de produtos fitossanitários.

Além dos desperdícios econômicos há ainda a crescente preocupação em virtude de seu potencial de risco ambiental (BARCELLOS; CARVALHO; SILVA, 1998). Muitas vezes, o ingrediente ativo se perde devido às condições do ambiente e horários de aplicação inadequados. A temperatura alta e a umidade relativa do ar baixa têm importante efeito sobre a pulverização de produtos fitossanitários, causando evaporação mais rápida das gotas. Portanto, é aconselhável que as pulverizações com produtos fitossanitários sejam realizadas pela manhã e ao final da tarde, a fim de evitar a evaporação rápida do produto aplicado (MATUO, 1990).

O objetivo deste trabalho foi avaliar a variação da deposição da calda de pulverização em variadas condições de temperatura e umidade relativa do ar nos diferentes horários de aplicação de três tipos de pontas de aplicação. 


\section{Material e Métodos}

O experimento foi realizado no dia 17/03/04, ao ar livre no campus da Universidade Estadual de Londrina, local com classificação climática Cfa, segundo Koëpen. Utilizou-se um pulverizador costal manual, equipado com válvula de pressão constante de $200 \mathrm{kPa}$. A caracterização dos tratamentos, assim como a caracterização das pontas utilizadas, gotas produzidas e respectivas vazões, estão representadas na Tabela 1.

Tabela 1. Tratamentos, modelos e tipos de pontas, classificação das gotas produzidas e respectivas vazões.

\begin{tabular}{ccccc}
\hline Tratamento & Modelo & Tipo de ponta & Classificação das gotas produzidas & $\begin{array}{c}\text { Vazão } \\
\left(\mathrm{L} \mathrm{min}^{-1}\right)\end{array}$ \\
\hline 1 & JA-1 & Jato cônico vazio & Muito finas a finas & 0,5 \\
2 & ADI-03 & $\begin{array}{c}\text { Jato plano (leque) } \\
\text { com pré-orifício }\end{array}$ & Médias a grossas & 1,0 \\
3 & BJ-03 & $\begin{array}{c}\text { Jato plano (leque) } \\
\text { com indução de ar }\end{array}$ & Grossas a muito grossas & 0,84 \\
\hline
\end{tabular}

A calda utilizada foi uma mistura de água com $\mathrm{KCl}$ (cloreto de potássio), a $20 \%$ em peso. As aplicações foram realizadas sobre copos descartáveis de PVC vazios, dispostos $0,5 \mathrm{~m}$ abaixo da ponta de pulverização. Um guia de arame foi montado para garantir que as aplicações fossem realizadas sempre na mesma distância e posição do alvo. As aplicações foram realizadas sempre pela mesma pessoa de maneira que a velocidade de deslocamento, de aproximadamente $3 \mathrm{~km} \mathrm{~h}^{-1}$, fosse a mais uniforme possível e, por conseqüência, o volume aplicado também. Cortinas de plástico foram dispostas lateralmente de maneira a evitar possíveis interferências do vento. A variação dos valores de temperatura e umidade relativa do ar é típica para cada local, horário e época do ano. Os dados de temperatura e umidade relativa do ar nos horários de aplicação foram obtidos junto às estações meteorológicas do Instituto Agronômico do Paraná - IAPAR e da Empresa Brasileira de Pesquisa Agropecuária - EMBRAPA SOJA, em Londrina/ $\mathrm{PR}$, e estão representados na Figura 1.
TEMPERATURA DO AR

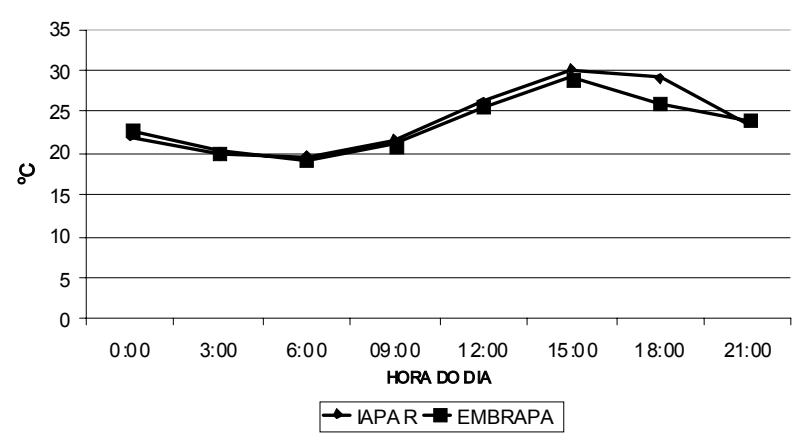

UMIDADE RELATIVA DO AR

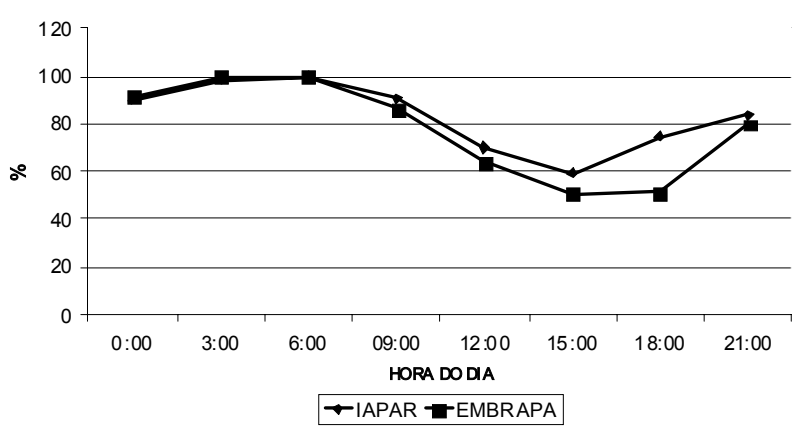

Figura 1. Temperaturas e umidade relativa do ar nos respectivos horários de aplicação. 
Para cada ponta foram coletadas 10 amostras em cada horário aplicação, com 4 repetições, totalizando 120 amostras por horário de aplicação e 960 amostras no experimento. A cada copo de PVC foram adicionados $50 \mathrm{~mL}$ de água destilada e deionizada. A deposição foi estimada através da condutividade elétrica da solução salina, através de um condutivímetro digital portátil. A relação entre a condutividade elétrica da solução e a deposição da calda de pulverização é método consagrado de avaliação, conforme ABI SAAB (2000). Os valores da condutividade elétrica foram corrigidos em função da vazão, como se todas as pontas tivessem a mesma vazão de $1 \mathrm{~L} \mathrm{~min}^{-1}$, para permitir a comparação. As análises estatísticas foram feitas através da análise de variância complementada com o teste de Tukey para comparação de médias.

\section{Resultados e Discussão}

Os valores da condutividade elétrica da solução de lavagem dos alvos de pulverização são apresentados nas Figuras 2 e 3, respectivamente para as pontas de pulverização e horários de aplicação.
Como esperado, na comparação dos horários de aplicação em cada tipo de ponta (Figura 2), pode-se notar que a deposição resultante da ponta JA-1 (jato cônico vazio, gotas muito finas a finas) diminui significativamente à medida que a temperatura aumenta e umidade relativa do ar diminui, sendo consoante ao disposto por MATTHEWS (1979). No caso da ponta ADI-03 (jato plano, gotas médias a grossas) ouve uma inesperada elevação significativa no valor dos depósitos no horário das nove horas, sem relação com os valores de temperatura e umidade relativa do ar. Contaminação das amostras analisadas ou aplicação feita em velocidade muito abaixo da prevista são possíveis causas desta distorção. Já a ponta BJ-03 (indução de ar, gotas grossas a muito grossas) não apresentou alteração significativa de deposição em nenhum dos horários, ou seja, não afetada significativamente pela variação da temperatura e umidade relativa do ar, confirmando o anunciado pelo fabricante das pontas de pulverização (JACTO, 1999). Comparando as pontas de maneira geral, em cada horário de aplicação e suas respectivas temperaturas e umidades relativas do ar (Figura 3), pode-se considerar que os resultados são os esperados.

\section{Resultados de Deposição X Pontas X Horários.}

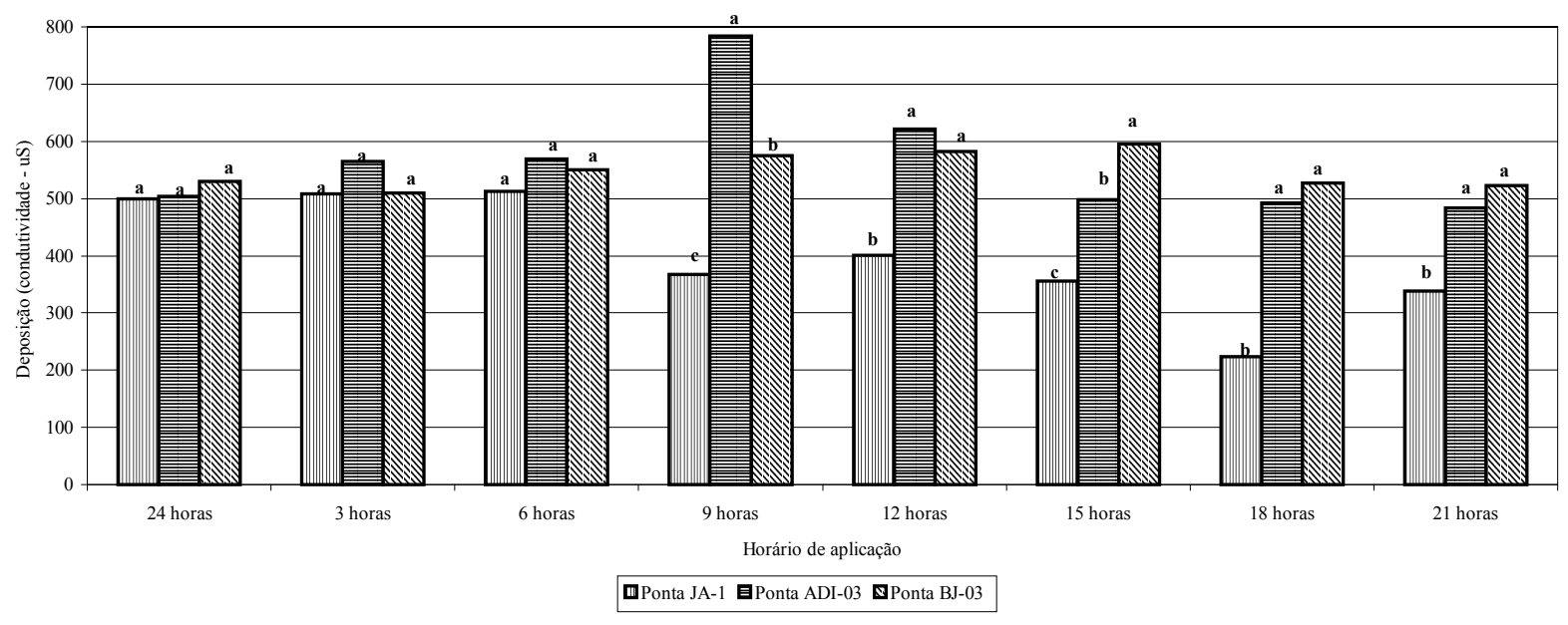

Colunas encimadas de mesma letra não diferem estatisticamente entre si pelo teste de Tukey $(\mathrm{P} \leq 0,01)$

Figura 2. Condutividade elétrica da solução de lavagem de alvos de pulverização para 3 tipos de pontas de pulverização em 8 horários de aplicação. 
Deposição x P onta s x Horários

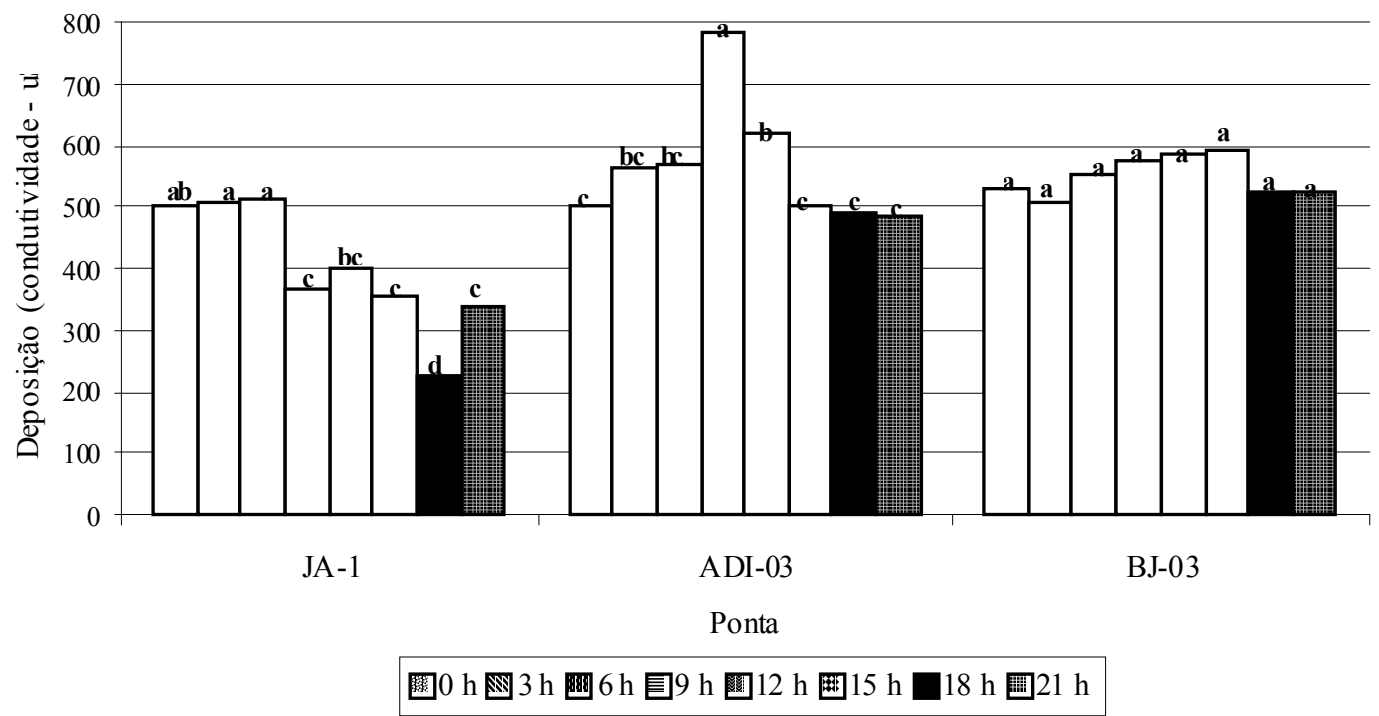

Colunas encimadas de mesma letra não diferem estatisticamente entre si pelo teste de Tukey $(\mathrm{P} \leq 0,01)$

Figura 3. Condutividade elétrica da solução de lavagem de alvos de pulverização para 8 horários de aplicação com 3 tipos de pontas de pulverização.

É interessante ressaltar que ponta BJ-03, no geral, não promoveu deposição significativamente superior à ponta $\mathrm{ADI}-03$, possivelmente por não haver presença de vento. A realização de novos experimentos com a presença de vento pode fornecer informações interessantes a respeito da capacidade das pontas chamadas com indução de ar de efetivamente diminuir a deriva. Também se destaca que no caso da ponta JA-1 há variação de mais de $100 \%$ entre os horários, com maior e menor deposição. De maneira geral os resultados reforçam a importância da escolha correta da ponta de pulverização, em função da temperatura e umidade relativa do ar. No caso da aplicação que exija gotas finas ou muito finas é fundamental que se atente para as condições climáticas no momento da aplicação, até interrompendo-a no caso de grandes adversidades.

\section{Conclusões}

As pontas de pulverização ADI-03 e BJ-03 não tiveram sua deposição afetada significativamente pela variação da temperatura e umidade relativa do ar durante os horários de avaliação e não diferiram entre si. Já a deposição da calda de aplicação da ponta JA-1 é significativamente reduzida com o aumento da temperatura e diminuição da umidade relativa do ar, chegando a variar em mais de $100 \%$ entre os valores extremos observados no presente trabalho.

\section{Referências}

ABI SAAB, O. J. G. Avaliação da cobertura e depósitos de agrotóxicos em videiras com o uso de diferentes técnicas de aplicação e condições operacionais. 2000. Tese (Doutorado em Agronomia) - Faculdade de Ciências Agronômicas, Universidade Estadual Paulista, Botucatu.

BARCELLOS, L. C.; CARVALHO, Y.C.; SILVA, A. L. Estudo sobre a penetração de gotas de pulverização no dossel da cultura da soja [Glycine max. (L.) Merrill]. Engenharia na Agricultura, Viçosa, v. 6, n. 2, p. 81-94, 1998.

BUISMAN, P.; SUNDARAM, K. M. S.; SUNDARAM, A.; TRAMMEL, K. Field deposit patterns of a diflubenzuron spray mix, after application to apple orchard using an airblast sprayer, and a laboratory evaluation of physical properties and atomization characteristics. 
Journal of Environmental Science and Health, New York, v. 24, n. 4, p. 389-411, 1989.

CARRERO, J. M. Maquinaria para tratamientos fitossanitários. Madrid: Mundi-Prensa, 1996.

CHAIM, A.; VALARINI, P. J.; PIO, L. C. Avaliação de perdas na pulverização de agrotóxicos na cultura do feijão. Pesticidas: Revista de Ecotoxicologia e Meio Ambiente, Curitiba, v. 10, p. 13-22, 2000.

CHRISTOFOLETTI, J. C. Considerações sobre tecnologia de aplicação de defensivos agrícolas. Diadema, SP: Spraying Systems do Brasil Ltda, 1997.

CHRISTOFOLETTI, J. C. Considerações sobre a deriva nas pulverizações agrícolas e seu controle. São Paulo: Teejet South América, 1999.

CUNHA, J. P. A. R.; TEIXEIRA, M. M.; COURY, J. R.; FERREIRA, R. L. Avaliação de estratégias para redução da deriva de agrotóxicos em pulverizações hidráulicas. Planta Daninha, Viçosa, v. 21, n. 2, p. 325-332, 2003.

JACTO: bicos Jacto de pulverização. São Paulo: Máquinas Agrícolas Jacto S.A. 1999. Folder

MATTHEWS, G. A. Pesticide application methods. New York: Longman, 1979.
MATUO, T. Técnicas de aplicação de defensivos agricolas. Jaboticabal: FUNEP, 1990.

PERGHER, G.; GUBIANI, R.; TONETTO, G. Foliar deposition and pesticide losses from three air-assisted sprayers in a hedgerow vineyard. Crop Protection, Oxford, v. 16, n. 1, p. 25-33, 1997.

SOARES, J.; LEÃO, M. Optimização da pulverização em médio e baixo volume na produção integrada de pêra rocha. Disponível em: <www.bayercropscience.pt/ download/pi_pera_rocha.pdf>. Acesso em: 19 abr. 2008.

TEIXEIRA, M. M. Influencia del volumen de caldo y de la uniformidad de distribuición transversal sobre la eficacia de la pulverización hidráulica. 1997. Tese (Doutorado em Agronomia) - Escuela Técnica Superior de Ingenieros Agrônomos, Universidad Politécnica de Madrid, Madrid.

TEWARI, V. K.; MURALIKRISHNA, R. V. S.; PANDYA, A. C. Performance evaluation and computer aided design of valve type hollow cone nozzles. St. Joseph: ASAE, 1998.

WOMAC, A. R.; GOODWIN, J. C.; HART, W. E. Comprehensive evaluation of droplet spectra from drift reduction nozzles. St. Joseph: ASAE, 1997. 